\title{
Bisphosphonate-induced osteonecrosis of the jaws: a literature review
}

\author{
Nayane de Andrade Teófilo 1*, Caio Denardin 2, Thiago Quirino Mota da Silva 3, Túlio Garcia Margute \\ 4, Andrei Rabenschlag Rossato 5, Max Soares Maione 6, Tiago Garcia Margute 6, \\ Igor Fonseca dos Santos 7
}

${ }^{1}$ CEULP-ULBRA, Palmas, TO, Brazil.

${ }^{2}$ Department of Periodontics, ITPAC, TO, Araguaina, Brazil.

3Department of Implantology, CEUMA, MA, São Luis, Brazil.

4 Department of Phrostodontics, FACOP, SP, Bauru, Brazil.

5 Medical student, Faculdade de Medicina, UnirG, Paraiso do Tocantins/TO, Brazil.

6 Department of Implantology, FACOP, SP, Bauru, Brazil.

7 Department of Medicine and Dentistry, UNIRG, Paraíso do Tocantins, CEULP-ULBRA, IOA, Palmas, TO

Tocantins, TO, Brazil.

*Corresponding author: Igor Fonseca dos Santos.1404 Sul, Alameda 10, QI 04, LT01 CS05. Palmas. Zip Code:77024-768 - Tocantins, Brazil Acronym of State, Country. Phone: +55 (63) 99299-1654. E-mail: igorfarmaodonto@gmail.com.

Received on: Nov 11, 2021. Accepted on: Dec 2, 2021. Available online: Dec 07, 2021.

\begin{abstract}
Bisphosphonates are widely used, whether in osteoporosis or malignant bone disorders. Therefore, it is necessary that there is sufficient knowledge about the adverse effects of this drug, especially in relation to Osteonecrosis of the Jaws Developed by Bisphosphonates, which is a pathology generated in the gnathic bones. So, the following question was asked in the research problem: What is the current situation regarding the use of bisphosphonates and the onset of osteonecrosis of the jaw? Searches were carried out on digital library websites in search of articles and research in books by renowned authors. Inclusion and exclusion criteria for articles found were defined. The verification of each article was carried out so that it could have perspective and follow-up on the subject discussed. The following databases were used: PUBMED, BIREME and LILACS, and SCIELO between the years 2007 to 2019. It was concluded then that Bisphosphonates play a very important role as a cause of osteonecrosis of the jaws, where the prognosis will be worse if the patient is treated with intravenous rather than oral types.
\end{abstract}

Keywords: Bisphosphonates; Osteonecrosis; Jaws.

\section{Introduction}

Bisphosphonates (BFF) are antiresorptive drugs analogous to pyrophosphate (a natural inhibitor of bone resorption). Its main action is the inhibition of bone resorption, having two routes of administration: oral and 
intravenous, are being used in a range of disease treatment, such as bone disorders such as osteoporosis, pagets disease, metastatic bone disease and myeloma. They will act on the following pathologies: when excessive osteoclast activity occurs, with changes in calcium and bone metabolism, primary and secondary hyperparathyroidism, osteoporosis, cancer-related moderate to severe hypercalcemia, metastatic lesions associated with breast cancer, and associated multiple myeloma with chemotherapies, being the most appropriate intravenous use for the case [1-2].

The action mechanism of bisphosphonates in the body will happen as follows: this drug has a great affinity for the hydroxyapatite present in the bone, causing it to remain in the bloodstream for a shorter time. They will reduce osteoclastic activities and, consequently, reduce bone resorption and increase density. The BFF will adhere to the bone when it has osteoclastic activity, that is, the concentration of this drug is increased in the bone when the osteoclasts exert activity [3].

Bone is an active structure, where remodeling occurs over time so that it has strength and mineral homeostasis. This remodeling is coordinated at first by two cells, the osteoclast that makes the resorption and the osteoblast that forms the bone. The growth and resorption factor are different for each type of bone, but the mechanism of action is the same for everyone. All bone tissues have non-linear elastic or porous viscoelastic. The three main action cells are: osteoblast, osteocytes and osteoclasts. So, osteoblasts and osteoclasts are cells that determine bone synthesis or resorption, whereas osteocytes are called sensory cells, they produce a feedback signal (reaction) and it is believed that it is produced as a response of energy deformation density [4-5].

The mandible is a bone structure that involves dental structures, and its osteogenesis formation occurs through the condensation of mesenchymal cells. Bone pathologies will depend on hormonal factors such as parathyroid, calcitrol, sex steroids, calcitonin, growth hormone, insulin growth factor, transformed growth factor beta, glucocorticoids, cytokines and others. Therefore, there needs to be hormonal balance and cells such as osteocytes, osteoblasts, osteoclasts and fibroblasts for non-pathological physiological remodeling to occur, and all bone diseases occur due to a disorder in this remodeling [6-8].

Osteonecrosis is a pathology that presents clinical signs and symptoms, in addition to having histopathological changes and clinical similarities, the 
main diseases mentioned in this article will have similar images as in computed tomography and panoramic radiography exams. The necrosis of the gnathic bones can occur depending on several factors, according to the literature, whether due to antiresorptive and anti-angiogenic medications, head and neck radiotherapy, reduced vascularization, trauma, pathologies or infections.

In 2003, the Bisphosphonaterelated Osteonecrosis of the Jaws (BRONJ) started to appear in the literature, therefore, it is a relatively new subject, where there are constant searches about this disease. BRONJ can be developed spontaneously or due to trauma, it has a behavior that is difficult to control and may not feel pain, where there is spontaneous bone exposure or wound that does not promote healing [9-11].

\section{Methodology}

This research refers to the literature review, where the search for the topic is relevant for dentists. A question was created which would be answered in searches for articles and books by renowned authors. Inclusion and exclusion criteria for articles found in digital libraries were defined.

The verification of each article was carried out so that it could have perspective and follow-up on the subject discussed.

The following question was asked: What is the current situation regarding the use of bisphosphonates and the onset of osteonecrosis of the jaw?.

The following keywords were used according to Decs (Health Science Descriptors):

Bisphosphonates, Osteonecrosis, Pharmacology, Jaw, Physiological, Pathology, Treatment, Radiographic, Aspect, Bone Remodeling and Dentistry. The following databases were explored: PUBMED, LILACS and BIREME (BVS) and SCIELO. For inclusion criteria, articles of any type of language were read, from the years 2007 to 2019 that were coherent with the subject, and articles prior to 2007 were excluded and that did not verify a relationship with the subject discussed.

Keyword crossings were made on digital library sites such as PUBMED, BIREME and LILACS (BVS), and SCIELO so that they could reach a number of articles and these articles were selected only from 2007 to 2019.

\section{Results (Review)}

According to George [12], bisphosphonates are chemotherapeutic compounds that accumulate in the bone matrix mainly in areas of high activity. They act on osteoclasts so that they can inhibit resorption and make it decrease, for example, the risk of fractures in 
patients who have osteoporosis. Therefore, in addition to apoptosis of osteoclasts, they allow osteocytes to remain in the bone, causing them to develop micro-cracks and reducing mechanical bone integrity. Also, according to Holstein [8], says that BFF are used in various treatments for bone disorders, are administered intravenously or orally, they will be distributed in the bones quickly, as they will leave the bloodstream slightly.

According to Jung [13], in addition to targeting the activity of osteoclasts, they will play a role in controlling the deregulated bone metabolism. It will act on several cells, such as compromising the function of fibroblasts, blood vessel cells, compromising keratinocytes, osteoblasts and osteoclasts, re-epithelialization and mucosal nutrition, and it is these cells that enable bone repair and surrounding tissue.

Kates and Ackert-Bicknell [14] say in their work that bisphosphonates will have a high affinity for calcium in the body and will focus on sites of active remodeling. Whether nitrogenous or not, the two classes will be introduced into the bone through the hydroxyapatite present, so that even if there is remodeling, they remain fixed in the bone and when the bone tissue is undergoing remodeling and this drug is present, they will be released into the acidic lacunae created by osteoclasts and will be absorbed by these cells. In agreement, Koy et al. [15] report that they refer to the inhibition of the recruitment and maturation of osteoclasts and their precursors, and that apoptosis still takes place. Therefore, BFF will negatively affect the adhesion activity of osteoclasts. The authors also point out that Zoledronate is the most potent bisphosphonate and that it automatically has more affinity with bone tissue, and its indication is for intravenous use in malignant diseases.

Also according to Gavaldá and Balgán [16], the predominance of BFF causing BRONJ will be greater if the patient is treated with intravenous types than orally, and they also report that some authors do not consider oral BFF as a risk factor for the occurrence of BRONJ, but he points out that the prevalence of occurrence may vary according to each type of study, but in his research the prevalence of oral BFF causing BRONJ was $0.001 \%$ to $0.10 \%$, when treatment lasts from four years onwards, this prevalence may vary in $0.21 \%$ and in short treatments can vary to $0.04 \%$.

Accordingly, Zhao [17], his studies reveal that patients with osteoporosis who used oral bisphosphonates had an incidence of $0.01 \%$ to $0.04 \%$ of incidence of BRONJ, whereas cancer patients who used 
injectable BFF had an incidence of $0.88 \%$ to $1.15 \%$.

According to Bermúdez-Bejarano et al. [18], they say that there are two possibilities for BRONJ to occur, the first is the drug's mechanism of action, which works by impairing normal bone remodeling, impairing angiogenesis, increasing soft tissue toxicity and it still allows for modulation to occur in the immune system disorder. The second alternative that can trigger BRONJ would be local factors such as oral surgery, prosthetic trauma, mandibular or palate torsos, ulcers and others. In agreement, Zhao [17] also says that the type of bisphosphonate such as disodium pamidronate and zoledronic acid increases the chances of developing NBMO. Thus, the use of injectable BFF is more likely than the oral use, and yet the use of oral aledronate in recent times increased the incidence rate from $0.23 \%$ to $0.92 \%$.

Vermeer [19] also reports, in agreement with other authors, that injectable BFF will contribute $5 \%$ to $20 \%$ in the incidence of NBMB after its use, having a greater threat than oral BFF, which has an occurrence of $0.04 \%$. It also coincides in your research in relation to other authors, that ONJ can be triggered after tooth extraction, periodontitis and trauma, which is associated in up to $84 \%$ of ONJ cases. He also reports that BFF are not the only ones to trigger BRONJ, which can occur by radiation to the head and neck.

It is noteworthy that the osteonecrosis of the jaws developed by BFF can be confused with other types of necrosis that are very similar in their clinical findings, according to Shuster [20], the existence of inflammation is in $100 \%$ of the cases of BRONJ and $0 \%$ in the cases. Therefore, the presence of bacteria in the medullary spaces occurs only in BRONJ, and in the cases of osteoradionecrosis and osteomyelitis the bacteria are only present on the surface of the lesion. Presence of osteoclasts in $96 \%$ of cases of BRONJ and practically none in cases of osteoradionecrosis and osteomyelitis.

The presence of inflammation was observed in most cases, as well as the presence of bacteria. However, inflammation cannot be used to differentiate the pathologies, as well as the bacteria that will be present in most cases, it is not possible to establish whether these bacteria are only in regions with marrow or only on the surface, however it is almost impossible to diagnose only with histological analysis, a diagnostic complement will be necessary, such as a complete anamnesis, clinical examination and image exam to assist in the correct diagnosis of the lesion and, consequently, its treatment. 
According to the studies by Rodriguez-Lozano and Oñate-Sánchez [21], the maintenance of BRONJ will have several treatments, such as surgical debridement, lesion resection, oxygen therapy and, ultimately, treatment with the use of mesenchymal cells. However, the severity and stage of the lesion is what will determine the type of treatment and several studies show that this type of treatment (conservative) was successful in only $20 \%$ of cases, while surgical treatment was successful in more than $85 \%$ of cases. There are two ways to perform the surgical treatment, but there are many contradictions in relation to this method, despite the percentage of success, the therapy consists of removing a good part of the bone so that the safety margin is guaranteed.

The Beth-Tasdogan research [22] shows that people diagnosed with NBMB should have treatment aimed at controlling the infectious process, reducing the progress of necrosis, and promoting tissue healing. Among the treatments, the non-surgical ones are antiseptic mouthwashes, antibiotic and fungal therapy, parathyroid and teriparatide hormones, pentoxifylline and $\alpha$-tocopherol, ozone therapy, hyperbaric oxygen therapy, low power laser therapy, preparations of growth factors such as platelet PRP and PRGF and also recombinant human bone morphogenetic proteins (rhBMPs). Surgical treatment includes sequestrectomy, surgical debridement, bone resection of the mandible and even extraction of teeth in necrotic bone.

However, El-Rabbany et al. [23] claim in their research that even with the evidence found in relation to the treatment of NBMB, there were few results from associated studies indicating high quality of the proposed treatments. The authors also reported that surgical intervention is likely to be effective over non-surgical treatment, also recommending flaps such as the mylohyoid for lesions involving the mucosa. They also say that there is a lack of quality in the proposed researches such as low power laser, pentoxifylline, ozone therapy or even the discontinuation of anti-resorptive drugs, causing a lack of results. Indicate that there is more research on the control and treatment of BRONJ.

\section{Discussion and Conclusion}

Bisphosphonates play a very important role as a cause of osteonecrosis of the jaws, where the prognosis will be worse if the patient is treated with intravenous types rather than orally. It should be noted that some authors do not consider oral BFF to be a risk factor for the occurrence of $\mathrm{BRONJ}$, requiring further research on this information. 
It is of great importance that cancer patients who are going to undergo chemotherapy are referred to the dentist. And in relation to treatment, it is important that the patient using BFF, whether intravenous or oral, inform their doctor or dentist of any sign or symptom in their oral cavity, so that the correct treatment is carried out, the sooner it is once the pathology is diagnosed, the treatment will be less radical.

\section{References}

[1] Yagiela JA, Neidle EA, Dowd FJ. Farmacologia e Terapêutica para Dentistas. 6 ed. 2011:944.

[2] Maahs MAP. Associação entre o uso de bisfosfonatos e osteonecrose dos maxilares: estudo em ratos. Pontifícia Universidade Católica do Rio Grande do Sul, 2008. Dissertação de Pós-Graduação em Odontologia.

[3] Mendes JM. Bifosfonatos: Aspetos de segurança. Universidade Fernando Pessoa Faculdade de Ciências da Saúde, 2017. Dissertação de Mestrado em Ciências Farmacêuticas.

[4] Yi S, Lee H, Lee J, Lee K, Kim J, Kim Y, Park J, Kim K. Bone Remodeling: Histone Modifications as Fate Determinants of Bone Cell Differentiation. International Journal of Molecular Sciences. 2019;20(13):31-47.
[5] Giorgio I, Dell'Isola F, Andreaus U, Alzahrani F, Hayat T, Lekszycki T. On mechanically driven biological stimulus for bone remodeling as a diffusive phenomenon. Biomechanics And Modeling in Mechanobiology. 2019;18(6):1639-1663.

[6] Sayilekshmy M, Hansen RB, Delaissé JM, Rolighed L, Andersen TL, Heegaard AM. Innervation is higher above Bone Remodeling Surfaces and in Cortical Pores in Human Bone: Lessons from patients with primary hyperparathyroidism. Scientific Reports. 2019;9(1):53-61.

[7] Verselá B, Švandová E, Bobek J, Lesot H, Matalová E. Osteogenic and Angiogenic Profiles of Mandibular Bone-Forming Cells. Frontiers In Physiology. 2019;10(24):10-124

[8] Holstein SA. A patent review of bisphosphonates in treating bone disease. Expert Opinion on Therapeutic Patents. 2019;29(5):315-325.

[9] Antoni CC, Matsumoto MA, Da Silva AA, Curi MM, Santiago Júnior JF, Sassi LM, Cardoso CL. Medication-related osteonecrosis of the jaw, osteoradionecrosis, and osteomyelitis: A comparative histopathological study. Brazilian Oral Research. 2018;32(23)2332.

[10] Ribeiro GH, Chrun ES, Dutra KL, Daniel FI, Grando LJ. Osteonecrosis of the jaws: a review and update in 
etiology and treatment. Brazilian Journal of Otorhinolaryngology. 2018;84(1):102-108.

[11] Barin LM, Pillusky FM, Pasini MM, Danesi CC. Osteonecrosis of the jaws associated with bisphosphonates: a literature review. Rev. Odontol. Univ. 2016;28(2):126-134.

[12] George EL, Truesdell SL, Magyar $\mathrm{AL}$, Saunders MM. The effects of mechanically loaded osteocytes and inflammation on bone remodeling in a bisphosphonate-induced environment. Bone. 2019;127(1):460-473.

[13] Jung J, Park JS, Righesso L, Pabst AM, Al-Nawas B, Kwon YD, Walter C. Effects of an oral bisphosphonate and three intravenous bisphosphonates on several cell types in vitro. Clinical Oral Investigations. 2018;22(7):2527-2534.

[14] Kates SL, Ackert-Bicknell CL. How do bisphosphonates affect fracture healing?. Injury. 2016;47:65-68.

[15] Koy S, Schubert M, Koy J, Ney M, Lauer G, Sabotowski R. Bisphosphonatassoziierte Kiefernekrosen. Der Schmerz. 2015;29(2):171-178.

[16] Gavalda C, Bagan JV. Concept, diagnosis and classification of bisphosphonate-associated osteonecrosis of the jaws. A review of the literature. Medicina Oral Patología Oral y Cirugia Bucal. 2016;21(1):260-270.
[17] Zhao T, Zhong W, Xiao S. Review of bisphosphonate related osteonecrosis of the jaws. Journal of Clinical Otorhinolaryngology, Head, and Neck Surgery. 2016;30(7):589-592.

[18] Bermúdez-Bejarano EB, SerraraFigallo MA, Gutiérrez-Corrales A, Romero-Ruiz MM, Castillo-de-Oyagüe R, Gutiérrez-Pérez JL, Machuca-Portillo G, Torres-Lagares D. Analysis of different therapeutic protocols for osteonecrosis of the jaw associated with oral and intravenous bisphosphonates. Medicina oral, patologia oral y cirugía bucal. 2017;22(1):43-57.

[19] Vermeer JAF, Renders GAP, Everts $\mathrm{V}$. Osteonecrosis of the Jaw-a Bone Site-Specific Effect of Bisphosphonates. Current Osteoporosis Reports. 2016;14(5):219-225.

[20] Shuster A, Reiser V, Trejo L, Ianculovici C, Kleinman S, Kaplan I. Comparison of the histopathological characteristics of osteomyelitis, medication-related osteonecrosis of the jaw, and osteoradionecrosis. International Journal of Oral and Maxillofacial Surgery. 2019;48(1):17-22.

[21] Rodriguez-Lozano FJ, OñateSanchez RE. Treatment of osteonecrosis of the jaw related to bisphosphonates and other antiresorptive agents. Medicina Oral Patología Oral y Cirugia Bucal. 2016;21(1):595-600. 
[22] Beth-Tasdogan NH, Mayer B, Hussein $\mathrm{H}$, Zolk O. Interventions for managing medication-related osteonecrosis of the jaw. Cochrane Database of Systematic Reviews. 2016;(10):1-56.

[23] El-Rabbany M, Sgro A, Lam KD, Shah PS, Azarpazhooh A. Effectiveness of treatments for medication-related osteonecrosis of the jaw. The Journal of the American Dental Association. 2017;148(8):584-594.

Conflict of interest: The author declares no conflicts of interest.

Acknowledgements: None.

Funding: None.

How to cite this article: Teófilo NA, Denardin C, Silva TQM, Margute TG, Rossato AR, Maione MS, Margute TG, Santos IF. Bisphosphonate-induced osteonecrosis of the jaws: a literature review. Brazilian Journal of Case Reports. 2021 Oct-Dec;01(4):190-198. 